\title{
Synthesis, Characterization and Anionic Dye Sequestration Capacity of Cellulose Nanocrystals Derived From Sugarcane Bagasse: Experimental and Regression Modelling
}

Luqmon Azeez ( $\nabla$ luqman.azeez@uniosun.edu.ng )

Osun State University https://orcid.org/0000-0002-6415-3490

Ayoade L. Adejumo

Department of Chemical Engineering, Osun State University, Osogbo, Nigeria

Abdulrasaq 0. Oyedeji

Department of Science Laboratory Technology, Federal Polytechnic Ilaro, Nigeria

Hassan K. Busari

Department of Pure and Applied Chemistry, Osun State University, Osogbo, Nigeria

Research

Keywords: Adsorption capacity, sugarcane bagasse, cellulose nanocrystals, exothermic, polynomial regression model

Posted Date: July 28th, 2020

DOI: https://doi.org/10.21203/rs.3.rs-41638/v1

License: (c) (1) This work is licensed under a Creative Commons Attribution 4.0 International License.

Read Full License 
Synthesis, characterization and anionic dye sequestration capacity of cellulose nanocrystals derived from sugarcane bagasse: Experimental and regression modelling

Luqmon Azeez $^{1 *}$, Ayoade L. Adejumo ${ }^{2}$, Abdulrasaq O. Oyedeji ${ }^{3}$, Hassan K. Busari ${ }^{1}$

${ }^{1}$ Department of Pure and Applied Chemistry, Osun State University, Osogbo, Nigeria.

${ }^{2}$ Department of Chemical Engineering, Osun State University, Osogbo, Nigeria

${ }^{3}$ Department of Science Laboratory Technology, Federal Polytechnic Ilaro, Nigeria

*Corresponding author: luqman.azeez@ uniosun.edu.ng (orcid.org/0000-0002-6415-3490)

\begin{abstract}
This study reported the extraction of cellulose nanocrystals from sugarcane bagasse using acid hydrolysis method. Nanocrystals were characterized with scanning electron microscopy, energy dispersive X-ray, Fourier Transform Infra-Red spectroscopy and investigated for their adsorptive capacity for methyl orange (MO) sequestration. The disappearance of peaks at 1736 and $1429 \mathrm{~cm}^{-1}$ in addition to higher carbon content, greater crystallinity index from 1.09 to 1.21 , predominantly nano range of particles $(0.045-0.082 \mu \mathrm{m})$ and larger porosity are parameters that better-defined cellulose nanocrystals. A 2-fold improvement in monolayer adsorption capacity was obtained for cellulose nanocrystals $\left(432.17 \mathrm{mgg}^{-1}\right)$ described by Langmuir isotherm over bagasse (170.99 $\mathrm{mgg}^{-1}$ ) described by Freundlich isotherm. Adsorption processes on both adsorbents were spontaneous, exothermic and best fitted to pseudo second order kinetics ensuing chemisorption. Polynomial regression model appropriately predicted equations that best describe the effects of different batch adsorption parameters on MO removal with better fittingness than experimentally generated data.
\end{abstract}

Keywords: Adsorption capacity, sugarcane bagasse, cellulose nanocrystals, exothermic, polynomial regression model.

\title{
Introduction
}

As indispensable as water is, quality water is difficult to come by particularly with the surging increase in the population-needing comfort coupled with the establishment of microindustrial scale companies. Wastes generated at homes, companies and industries eventually find their ways into surface water thus degrading its quality (Assouline et al. 2015; Azeez et al. 2015, 2020a). This is expected to continue as the population continues to rise and more industries are created. Most pollutants that found their way into water bodies are non-easily biodegradable, recalcitrant, stable to oxidation and are as dangerous as their intermediates 
and secondary metabolites (Jiang et al. 2017; Gautam et al. 2019; Beh et al. 2020). Methyl orange (MO) is a complex, highly water soluble, azo-structured anionic dye that has found usefulness in laboratories, photography and textile but its discharge in water has been reported to interrupt ecological balance along with disruption of water quality parameters (Keyhanian et al. 2016; Huang et al. 2017; Zhang et al. 2017; Adejumo et al. 2020). Hence, holistic approaches to removing highly toxic MO should be employed to meet up with water demands of the populace.

Several methods ranging from flocculation, coagulation, adsorption, biological degradation, membrane filtration, electrochemical and reverse osmosis are in use for wastewater remediation. Adsorption has been the frequently applied remediation method due to its simplicity and other encouraging attributes. However, contending with drawbacks associated with some of the above-mentioned methods as well as expensiveness of many adsorbents, different studies have reported applications of inexpensive and readily available adsorbents especially activated carbons from waste materials. These are also not without limitations as typically used adsorbents are macro-scaled and therefore large quantities would be used to achieve excellent results (Munagapati et al. 2019; Pavithra et al. 2019; Azeez et al. 2018, 2020a,b).

Meanwhile, progression in nanotechnology has made remediation a lot easier owing to the intrinsic characteristics of nanostructured materials that possess enhanced adsorptive properties as against macro-scaled materials. Moreover, their inexpensive, renewable, biodegradable, retentive and regenerative properties are too encouraging to dismiss in addition to using small quantity to achieve greater results (Suman et al. 2015; Mahfoudhi et al. 2017; Theivasanthi et al. 2018).

Nanocellulose is an environmentally compliant, decomposable, inexhaustive and nonhazardous adsorbent having a diameter dimension less than $100 \mathrm{~nm}$ with enhanced reactive sites together with other characteristics suitable for environmental remediation (Nechyporchuk et al. 2016; Bano and Negi, 2017). Nanocellulose has found usefulness in medicine, food and construction applications in addition to the environmental remediation of wastes due to its biocompatibility, tensile strength, abundant hydroxyl groups, large surface area and low toxicity (Dufresne, 2013; Hosseinidoust et al. 2015; Jorfi and Johan, 2015; Abitbol et al. 2016; Hakkarainen et al. 2016; Phanthong et al. 2018; Wang et al. 2019). It has been deployed for remediating dyes, volatile organic compounds, polycyclic aromatic hydrocarbons, heavy metals and pollutants of their likes (Chan et al. 2015; Jiang et al. 2017; Adejumo et al. 2020; Beh et al. 2020). 
Nanocellulose is obtainable from cellulosic materials by modifying the crystallinity degree without disruption in functional group reactivities rather enhanced structural activities accompanied with improved morphological assemblage (Jiang et al. 2017; Beh et al. 2020). It is called cellulose nanofibers (CNFs) when it is extracted by mechanical processes and cellulose nanocrystals (CNC) when it is done using acid hydrolysis. Cellulose nanocrystals extracted by acid hydrolysis treatment have been extensively explored and are considered easier compared with other methods of nanocellulose syntheses (Jonoobi et al. 2015; Nechyporchuk et al. 2016; Oliveira et al. 2016; Theivasanthi et al. 2018). Nanocellulose has been prepared from widely available, abundant, cost-effective and renewable cellulosic materials such as corncob, corn straw, pineapple leaf, cassava bagasse, cotton, soy hulls, sago pith, kenaf core, rice straw, cocoa bean shell, bamboo, wood, banana leaf, newspaper, jute leaf, groundnut shell, wheat straw, sugarcane bagasse and flax fibre (Abraham et al. 2011; Neto et al. 2013; Pehlivan et al. 2013; Chan et al. 2015; Chen et al. 2011, 2015; Bano and Negi, 2017; El Achaby et al. 2018; Theivasanthi et al. 2018; Buthiyappan et al. 2019; Adejumo et al. 2020; Beh et al. 2020)

Sugarcane bagasse is a lignocellulosic fibrous residual waste from sugarcane (Saccharum officinarum) after sequencing its juice. It is widely available and litters carelessly in water and soil in Nigeria. It contains cellulose (45 - $55 \%)$, hemicellulose (25 - 35\%) and lignin (18 - $24 \%$ ) and serves as a major raw material for biodiesel production (Ferreira et al. 2018). The high proportion of cellulose in sugarcane bagasse implies its predominant crystallinity and allows for modification of amorphous region. It has been used as an adsorbent for dyes, heavy metals and pesticides due to its richness in carboxyl, phenolic and hydroxyl groups essential for adsorption (Alves et al. 2016; Maya and Anjali, 2018; Buthiyappan et al. 2019). However, most studies reported the application of modified sugarcane bagasse or produced activated carbon from it. Though they were found effective as adsorbents but the additional cost of production and modification could limit these processes (Brandão et al. 2010).

Extraction of nanocellulose from sugarcane bagasse is a better alternative owing to nondisruption of inherent chirality, available functional groups, biodegradability and biocompatibility with large surface area, enhanced surface functionality and adsorptive properties (Theivasanthi et al. 2018; Adejumo et al. 2020; Beh et al. 2020).

Consequent upon novel properties of nanocellulose and its wide applications, this study was aimed at extracting nanocellulose using acid hydrolysis from sugarcane bagasse as an adsorbent for simulated dye wastewater remediation as well as predict model equations that best describe the adsorption process using polynomial regression analysis 


\section{Materials and methods}

Sugarcane units were purchased at Oja-Oba market, Osogbo, Osun State, Nigeria. Sugarcane units were washed, peeled and its juice was extracted to leave residual bagasse. This was airdried, milled to powder and oven-dried at $80{ }^{\circ} \mathrm{C}$ for $5 \mathrm{~h}$ to completely remove moisture. The powdered sugarcane bagasse was sieved with $425 \mu \mathrm{m}$ mesh sieve and kept in a tight container for further use. All chemicals $\left(\mathrm{NaOH}, \mathrm{H}_{2} \mathrm{SO}_{4}\right.$, methyl orange) used are of analytical grade.

\section{Synthesis of cellulose nanocrystals and characterization}

The method of synthesis as described by Adejumo et al. (2020) was followed and is illustrated in the scheme (Figure 1). Fourier transform infrared spectroscopy (FTIR) (Model 500 , Buck Scientific Inc.) was recorded in the range of $400-4000 \mathrm{~cm}^{-1}$ with a resolution of 4 $\mathrm{cm}^{-1}$. Scanning electron microscopy coupled with energy dispersive X-ray was done with Jeol JSM-6400 for morphology and elemental composition.

\section{Adsorption studies}

\section{Methyl orange preparation and batch adsorption}

$100 \mathrm{mgL}^{-1}$ of $\mathrm{MO}$ was prepared and different concentrations ranging from $10-50 \mathrm{mgL}^{-1}$ were used for the adsorption study. Influence of operational variables on the sequestration of MO on bagasse and cellulose nanocrystals were studied. This was achieved by varying initial solution $\mathrm{pH}$ from 2 to 10 , initial MO concentrations from 10 to $50 \mathrm{mgL}^{-1}$, bagasse and cellulose nanocrystal dosage from 0.1 to $0.5 \mathrm{~g}$, contact time from 0 to $75 \mathrm{~min}$ as well as temperature from 303 to $315 \mathrm{~K}$. Batch adsorption was performed with $0.5 \mathrm{~g}$ of each adsorbent added to $50 \mathrm{mgL}^{-1} \mathrm{MO}$ in a conical flask placed in a water bath with shaker (Uniscope water bath shaker) thermostatically regulated at $303 \mathrm{~K}$ for $30 \mathrm{~min}$ and agitated at $300 \mathrm{rpm}$ for all parameters but for adsorbent dosage. Absorbance values were recorded at $480 \mathrm{~nm}$ with Jenway 6405 UV-Visible Spectrophotometer (Buch Scientific Inc. USA). The percentage sequestration of $\mathrm{MO}$ and quantity of $\mathrm{MO}$ adsorbed at a particular time were calculated using equations 1 and 2 respectively.

For determination of $\mathrm{pH}$ point of zero charges $\left(\mathrm{pH}_{\mathrm{pzc}}\right), 0.1 \mathrm{~g}$ of each adsorbent was added to $0.1 \mathrm{M} \mathrm{NaCl}$ solution $(200 \mathrm{ml})$ of known $\mathrm{pH}$ and adjusted to $\mathrm{pH}$ between 2 and 10 with $\mathrm{HCl}$ and $\mathrm{NaOH}$.

Batch adsorption was investigated by 
\% MO removal $=\frac{\left(C_{i}-C_{f}\right) \times 100}{C_{i}}$

$q_{t}=\frac{\left(C_{i}-C_{t}\right) V}{M}$

$q_{t}$ - amount of MO adsorbed per unit mass of adsorbent $\left(\mathrm{mgg}^{-1}\right)$ at time $\mathrm{t}, C_{i}$ - initial MO concentration $\left(\mathrm{mgL}^{-1}\right), C_{f}$ - final MO concentration $\left(\mathrm{mgL}^{-1}\right), C_{t}$ - concentration of $\mathrm{MO}$ remaining at time $\mathrm{t}, \mathrm{V}$ - Volume of MO solution (L) and M - mass of adsorbent (g).

\section{Adsorption isotherms}

Four adsorption isotherms with their appropriate equations listed in equations 3 to $6 \mathrm{~b}$ were applied to fit the equilibrium parameters between MO and adsorbents. The suitability of each model was predicted by comparing correlation coefficients $\left(\mathrm{R}^{2}\right)$; the closer it is to unity, the better it is for the description of an isotherm model.

Langmuir isotherm (Langmuir, 1918)

$\frac{C_{e}}{q_{e}}=\frac{C e}{q_{\max }}+\frac{1}{q_{\max K_{L}}}$

$R_{L}=\frac{1}{1+K_{L} C_{o}}$

Freundlich isotherm (Freundlich, 1906)

$\log q_{e}=\frac{1}{n} \log C_{e}+\log K_{f}$

Tempkin isotherm (Tempkin and Pyshev, 1940)

$$
\begin{gathered}
q_{e}=B \ln A+B \ln C_{e} \\
B=R T / b
\end{gathered}
$$

Dubinin-Radushkevich (Dubinin and Radushkevich, 1947)

$$
\ln q_{e}=\ln q_{o}-\beta \varepsilon^{2}
$$

$\varepsilon=R \operatorname{Rln}\left(1+\frac{1}{C_{e}}\right)$

$E=\sqrt{ } 1 / 2 \beta$

$C_{e^{-}}$equilibrium concentration of $\mathrm{MO}\left(\mathrm{mgL}^{-1}\right), q_{e^{-}}$quantity of $\mathrm{MO}$ adsorbed at equilibrium $\left(\mathrm{mgg}^{-1}\right), q_{\max }$ - maximum monolayer adsorption capacity $\left(\mathrm{mgg}^{-1}\right), K_{L^{-}}$Langmuir adsorption constant $\left(\mathrm{Lmg}^{-1}\right), \mathrm{R}_{\mathrm{L}^{-}}$Langmuir separation, $K_{f}$-Freundlich constants for binding energy, $n$ adsorption intensity, $\mathrm{b}\left(\mathrm{Jmol}^{-1}\right)$ - heat of absorption and $\mathrm{E}$-energy of adsorption.

\section{Adsorption kinetics}


Kinetic model studied for the fittingness of adsorption kinetics are listed in equations 7, 8 and 9. Adsorption mechanism was studied with intra-particle diffusion (eqn. 10). The suitability of each model for describing kinetic models was validated with correlation coefficient $\left(\mathrm{R}^{2}\right)$ and non-linear Chi-square test (eqn. 11).

Pseudo first order kinetics

$\ln \left(q_{e}-q_{t}\right)=\ln q_{e}-K_{1} t$

Pseudo second order kinetics

$\frac{t}{q_{t}}=\frac{1}{K_{2} q_{e}^{2}}+\frac{t}{q_{e}}$

Elovich kinetics

$q_{t}=\frac{1}{\beta} \ln (\alpha \beta)+\frac{1}{\beta} \ln t$

$q_{t}=K_{\text {diff }} t^{1 / 2}+C$

$\chi^{2}=\sum_{i=1}^{n} \frac{\left(q_{\text {exp }}-q_{c a l}\right)^{2}}{q_{c a l}}$

$q_{e}-$ quantity adsorbed at equilibrium $\left(\mathrm{mgg}^{-1}\right), q_{t}$ - quantity adsorbed at time $\mathrm{t}\left(\mathrm{mgg}^{-1}\right), K_{1}$ rate constant for the pseudo first order $\left(\mathrm{min}^{-1}\right), K_{2}$ - rate constant of the pseudo second order $\left(\mathrm{gmg}^{-1} \mathrm{~min}^{-1}\right), K_{\text {diff }}$ - rate constant of intraparticle diffusion $\left(\mathrm{mg} \mathrm{g}^{-1} \min ^{-1 / 2}\right), \alpha \quad$ chemisorption rate and $\beta$ - extent of surface coverage.

\section{Adsorption thermodynamics}

Parameters to describe adsorption thermodynamics were obtained from equations 12 and 13 .

$\ln K_{o}=\frac{\Delta S^{o}}{R}-\frac{\Delta H^{o}}{R T}$

$\Delta G^{o}=\Delta H-T \Delta S$

$\Delta \mathrm{S}^{\mathrm{o}}$ is change in entropy, $\Delta \mathrm{H}^{\mathrm{o}}$ is change in enthalpy and $\Delta \mathrm{G}^{\mathrm{o}}$ is change in free energy

\section{Polynomial regression prediction of adsorption process}

Data generated from adsorption isotherm, kinetics and thermodynamics were fitted to polynomial linear regression to predict optimum conditions that best describe the adsorption of MO on bagasse and cellulose nanocrystals. The polynomial regression model for prediction is based on equation 14 where a set of $x$ interaction variables are modelled to obtain dependent $y$. The predictive agreement between experimentally generated and model predicted data was determined using correlation coefficient $\mathrm{R}^{2}$ and statistical significance at $95 \%$ confidence level. The predicted equations and validations for all experimental data are presented along with each batch adsorption parameter. 
$y=\beta_{o}+\beta_{1} x+\beta_{2} x^{2}$

Where $\beta_{o}, \beta_{1}, \beta_{2}$ are intercepts of model

\section{Results and discussion}

\section{Characterization of bagasse and cellulose nanocrystals}

Scanning electron microscopy coupled with EDX was used to study morphological arrangement, particle size and elemental compositions of bagasse (Fig. 2a) and synthesized cellulose nanocrystals (Fig 2b). Diameters of particles of bagasse range between 2.0 and 6.4 $\mu \mathrm{m}$ with predominant particles having sizes between 3.1 and $4.2 \mu \mathrm{m}$ (insert). Cellulose nanocrystals are nearly oval having particles in the range 0.045 to $0.193 \mu \mathrm{m}$ predominantly between 0.045 and $0.082 \mu \mathrm{m}$ (insert). The image of bagasse shows a more compressed morphology while the image of cellulose nanocrystal reveals a better porous morphology. These ranges and characteristics indicate nanostructure morphology of cellulose nanocrystals vital for adsorption processes (Chan et al. 2015; Yang et al. 2017a,b; Phanthong et al. 2018).

Cellulose nanocrystals contain higher weight percentage of carbon, silicon and lower weight percentage of oxygen compared to bagasse as obtained in EDX results (Fig. 2a and 2b). This implies a better adsorptive property for cellulose nanocrystals since adsorption capacity is a function of carbon content (Ojedokun and Bello, 2017; Buthiyappan et al. 2019).

To study the surface chemistry of both adsorbents, FTIR characterization spectra (Fig. 4) reveal major functional groups in bagasse (BG) and cellulose nanocrystals (NBG). Peaks at 3414 and $1053 \mathrm{~cm}^{-1}$ in $\mathrm{BG}$ indicate the presence of stretching vibrations of $\mathrm{OH}$ and asymmetric cellulosic bridges of C-O-C groups respectively whereas they occur at 3418 and $1047 \mathrm{~cm}^{-1}$ in cellulose nanocrystals. Peaks from 2897 to $2941 \mathrm{~cm}^{-1}$ in both adsorbents correspond to $\mathrm{C}-\mathrm{H}$ of methyl and methylene. Peaks at 1736 and $1429 \mathrm{~cm}^{-1}$ signify the presence of uronic and acetyl $\mathrm{C}=\mathrm{O}$ and $\mathrm{C}-\mathrm{O}$ of esters from lignin and hemicellulose in $\mathrm{BG}$ but had disappeared in cellulose nanocrystals. Appearance of peak at $1121 \mathrm{~cm}^{-1}$ in cellulose nanocrystals attributed to $\mathrm{SO}_{4}{ }^{2-}$ is an attestation of $\mathrm{H}_{2} \mathrm{SO}_{4}$ hydrolysis (Nechyporchuk et al., 2016). This implies a more crystalline cellulosic material in cellulose nanocrystals since hemicellulose and lignin are the amorphous regions in lignocellulose. Peaks between $1600-$ $1638 \mathrm{~cm}^{-1}$ correspond to bending vibrations of $\mathrm{OH}$ associated with adsorbed water. Peaks in BG and cellulose nanocrystals spectra are representative of lignocellulose and nanocellulose reported in the literature. Moreover, the FTIR characterization indicates the retention of inherent cellulosic nature of BG in cellulose nanocrystals with complete removal of lignin and hemicellulose (Liu et al. 2016; Bano and Negi, 2017; Maya and Anjali, 2018; Ferreira et 
al. 2018; Theivasanthi et al. 2018; Buthiyappan et al. 2019; Adejumo et al. 2020; Beh et al. 2020.

Further analysis of FTIR data on crystallinity index, degree of the disordered region and hydrogen bonding pattern were explored. Total crystallinity index (CI) was determined as the ratio of absorbance intensities of crystalline bands at 1373 to $2900 \mathrm{~cm}^{-1}$ while lateral order index (LOI) is the ratio of 1433 to $895 \mathrm{~cm}^{-1}$ proposed by Hurtubise and Krassig (1960) and Nelson and O' Connor (1964). The energy of hydrogen bonding $\left(\mathrm{E}_{\mathrm{H}}\right)$ is described by equation 15. Crystallinity index and energy of hydrogen bonding are parameters to assess orderliness/crystallinity of a cellulosic material (Kumar et al. 2014; Bano and Negi, 2017; Kruer-Zerhusen et al. 2018).

$E_{H}=\frac{1}{K} *\left(\frac{v_{0}-v}{v_{0}}\right)$

Where $\mathrm{k}$ is $1.68 \mathrm{E}-2, v_{0}$ and $v$ are frequencies of free hydrogen bonded $\mathrm{OH}\left(3600 \mathrm{~cm}^{-1}\right)$ and hydrogen bonded $\mathrm{OH}$ respectively.

The increase in values of CI, LOI and $\mathrm{E}_{\mathrm{H}}$ from 1.09 to $1.21,1.23$ to 1.33 and 27.96 to 29.17 kcal imply an improvement in structural crystallinity and regularity of cellulose nanocrystals over bagasse. This aligned with results of Bano and Negi (2017) and Kruer-Zerhusen et al. (2018). The increased crystallinity index could be connected to the removal of amorphous regions of hemicellulose and lignin during $\mathrm{NaOH}$ treatment as obtained in FTIR and better ordered crystalline region due to formation of new hydrogen bonds (Zhang et al. 2013; Beh et al. 2020)

\section{Effects of different parameters on batch adsorption studies}

The surface charges play a prominent role in the adsorption process and as obtained for both adsorbents revealed by $\mathrm{pH}$ point of zero charge $\left(\mathrm{pH}_{\mathrm{pzc}}\right)$, cellulose nanocrystals and bagasse were cationic below $\mathrm{pH}_{\mathrm{pzc}} 4.1$ and 8.3 respectively. At these values $\left(\mathrm{pH}_{\mathrm{pzc}}\right)$, both adsorbents had zero net charge while they would be positively charged at $\mathrm{pH}<\mathrm{pH}_{\mathrm{pzc}}$ and negatively charged at $\mathrm{pH}>\mathrm{pH}_{\mathrm{pzc}}$. Expectedly, maximum removal of $\mathrm{MO}$ on these adsorbents occurred at $\mathrm{pH} 3$ and 6 for cellulose nanocrystals and bagasse respectively (Fig. 4). Adsorption was maximum at these $\mathrm{pH}$ values due to electrostatic interaction between cationic surfaces of adsorbents (cationic at $\mathrm{pH}<\mathrm{pH}_{\mathrm{pzc}}$ ) and anionic MO (Huang et al. 2017; Ojo et al. 2017; Moawad et al. 2020). There was an initial increase in percentage removal of MO on cellulose nanocrystals from $\mathrm{pH} 2$ to 3 after which it dropped sizably till $\mathrm{pH} 10$ while there was a gradual decrease in percentage removal of $\mathrm{MO}$ on bagasse from $\mathrm{pH} 2$ to 5 followed by 
an increase at $\mathrm{pH} 6$ and thereafter dropped till $\mathrm{pH}$ 10. Prediction of effects of $\mathrm{pH}$ on percentage removal of MO modelled with polynomial regression follows equations 16a and $16 \mathrm{~b}$ for bagasse and cellulose nanocrystals respectively. There was high accuracy $\left(\mathrm{R}^{2}=\right.$ 0.928) and statistically insignificant variations although with lower percentages between experimentally and predicted percentages of removal of MO on cellulose nanocrystals (Fig. 4). Conversely, the agreement between experimentally and predicted percentages of removal of MO on bagasse (Fig. 4) was significantly low $\left(\mathrm{R}^{2}=0.015\right)$.

$$
\begin{array}{lll}
y=68.59+0.071 x-0.006 x^{2} & \left(\mathrm{R}^{2}=0.015, \mathrm{p}=0.985\right) & 16 \mathrm{a} \\
y=64.75-0.188 x+0.007 x^{2} & \left(\mathrm{R}^{2}=0.928, \mathrm{p}=0.072\right) & 16 \mathrm{~b}
\end{array}
$$

Percentage uptake of MO on different dosages of cellulose nanocrystals increased from $69-78 \%$ whereas a slight reduction in the percentage of adsorption on bagasse with an increase in dosage from 57.6 - $56.8 \%$ was obtained. The increase in percentage adsorption recorded for nanocrystals may be connected to the availability of larger surface and more reactive sites for MO uptake. It is equally implying adsorption on the surface of nanocrystals. Conversely, reduction in the percentage of uptake on bagasse could be due to compactness of bagasse layers (Ojedokun and Bello, 2017; Suganya et al. 2017; Saravanan et al. 2019). Model equations of polynomial regression for predicting effects of dosage on percentage removal of $\mathrm{MO}$ are given as $17 \mathrm{a}$ and $17 \mathrm{~b}$ for bagasse and cellulose nanocrystals respectively. The model predicted similar trends of a strong agreement without significant difference for cellulose nanocrystals and an average correlation with significant disparities for bagasse between model predicted and experimentally generated data.

$$
\begin{array}{lll}
y=57.34+0.228 x-0.006 x^{2} & \left(\mathrm{R}^{2}=0.57, \mathrm{p}=0.43\right) & 17 \mathrm{a} \\
y=66.99+1.31 x+0.178 x^{2} & \left(\mathrm{R}^{2}=0.99, \mathrm{p}=0.01\right) & 17 \mathrm{~b}
\end{array}
$$

Percentage sequestration of MO decreased with increase in the concentration of $\mathrm{MO}$ from 59.75 to $18.67 \%$ for cellulose nanocrystals and 51.08 to $6.63 \%$ for bagasse (Fig. 6) for lowest $\left(10 \mathrm{mgL}^{-1}\right)$ to the highest $\left(50 \mathrm{mgL}^{-1}\right)$ concentrations of MO. These reductions are related to the saturation of vacant reactive sites and pore spaces on both adsorbents (Suganya et al. 2017; Moawad et al. 2020). At low concentration, the ratio of MO molecules to adsorbent reactive sites was smaller hence higher percentage. However, as the MO concentrations increased, the ratio of MO molecules to adsorbent vacant reactive sites increased thus lower percentage. This agrees with reports of Anitha et al. (2016) and Ojo et al. (2017). The model predicted equations for initial concentrations of MO on bagasse and cellulose nanocrystals are given in equations $18 \mathrm{a}$ and $18 \mathrm{~b}$ respectively. Strong correlations 
with no significant differences between experimental and model data were obtained for both adsorbents. Regression model predicted an increase in the percentage of MO adsorbed with respect to initial concentrations on bagasse (Fig. 6)

$$
\begin{array}{lll}
y=80.80-29.94 x+2.52 x^{2} & \left(\mathrm{R}^{2}=0.89, \mathrm{p}=0.11\right) & 18 \mathrm{a} \\
y=73.22-20.64 x+1.86 x^{2} & \left(\mathrm{R}^{2}=0.98, \mathrm{p}=0.022\right) & 18 \mathrm{~b}
\end{array}
$$

The rate of adsorption with time was initially swift then became gradual until it attained equilibrium (Fig. 7) at 45 and 35 min for nanocrystals and bagasse respectively. This trend of swift uptake of MO is attributable to the initial driving force of MO to overcome the resistance of mass transfer and availability of vacant reactive sites on both adsorbents that got occupied as time progressed (Inyinbor et al. 2017; Ojedokun and Bello, 2017; Adekola et al. 2019). Regression model predicted equilibrium was attained at 20 and $15 \mathrm{~min}$ for bagasse and nanocrystals respectively following equations $19 \mathrm{a}$ and $19 \mathrm{~b}$. The predicted model values had significant correlations with experimental data with no significant variations.

$$
\begin{array}{lll}
y=75.57+1.37 x-0.03 x^{2} & \left(\mathrm{R}^{2}=0.94, \mathrm{p}=0.06\right) & 19 \mathrm{a} \\
y=81.72+1.19 x-0.03 x^{2} & \left(\mathrm{R}^{2}=0.98, \mathrm{p}=0.022\right) & 19 \mathrm{~b}
\end{array}
$$

Effects of temperature on the uptake of MO on both adsorbents were detailed between 303 - 323 K. Adsorption percentage decreased slightly insignificantly with increased temperature from 74.58 to $74.55 \%$ and 74.51 to $74.45 \%$ for nanocrystals and bagasse respectively. These reductions are an indication of exothermic nature of the adsorption process (Inyinbor et al. 2017; Ojedokun and Bello, 2017). Regression model predicted nonsignificantly varied close agreements between experimental and predicted data of effects of temperature on adsorption processing following equations 20a and $20 \mathrm{~b}$ for bagasse and nanocrystals respectively.

$$
\begin{array}{lll}
y=74.63-0.0028 x-0.0021 x^{2} & \left(\mathrm{R}^{2}=0.98, \mathrm{p}=0.022\right) & 20 \mathrm{a} \\
y=74.54-0.01 x+0.001 x^{2} & \left(\mathrm{R}^{2}=0.99, \mathrm{p}=0.011\right) & 20 \mathrm{~b}
\end{array}
$$

\section{Adsorption isotherms study}

Adsorption data were fitted to Langmuir, Freundlich, Tempkin and DubininRadushkevich isotherm to investigate the appropriateness of each isotherm for the description of adsorption process (Table 1). This was determined using correlation coefficient $\left(\mathrm{R}^{2}\right)$ closeness to unity; the closer to unity it is, the better it is for the description of the adsorption process. 
The suitability of each isotherm for adsorption process on bagasse is in order $\left(\mathrm{R}^{2}\right)$; Freundlich (0.92) > Dubinin-Radushkevich (0.91) > Langmuir (0.66) > Temkin (0.64). The order of fattiness of isotherm model $\left(\mathrm{R}^{2}\right)$ for cellulose nanocrystals follows Langmuir $(0.91)>$ Dubinin-Radushkevich (0.61) > Freundlich (0.60) > Temkin (0.56). Langmuir and Freundlich isotherms were the most appropriate to describe adsorption on cellulose nanocrystals and bagasse implying adsorption on the crystalline uniform surface of cellulose nanocrystals while it was on the heterogenous surface for bagasse. This is consonance with results of crystallinity indices calculated for both adsorbents.

Polynomial regression model predicted for both adsorbents were governed by Langmuir isotherm as obtained in correlation coefficients $\left(R_{N B G}^{2}-0.996, R_{B G}^{2}-0.94\right)$ while improved correlation coefficients $\left(\mathrm{R}^{2}\right)$ were predicted for cellulose nanocrystals in Freundlich (0.74), Temkin (0.74) and Dubinin-Radushkevich (0.98) isotherms, decrease in $\mathrm{R}^{2}$ values were predicted for bagasse in Freundlich $\left(\mathrm{R}^{2}=0.41\right)$, Temkin $(0.57)$ and Dubinin-Radushkevich (0.81) isotherms.

Maximum monolayer adsorption capacity $\left(q_{\max }\right)$ calculated from Langmuir isotherm for bagasse and cellulose nanocrystals are 170.99 and $432.17 \mathrm{mgg}^{-1}$ respectively. This is a 2-fold improvement in adsorption capacity of cellulose nanocrystals over bagasse. This is linked to higher carbon content and porosity in nanocrystals (Adejumo et al. 2020). Regression analysis predicted a marginal increase in $q_{\max }$ for nanocrystals $\left(437.06 \mathrm{mgg}^{-1}\right)$ and sizeable increase for bagasse $\left(246.12 \mathrm{mgg}^{-1}\right)$. Comparing $q_{\max }$ values of cellulose nanocrystals with previously reported values in other studies (Table 2), shows it is a far better adsorbent concerning performance for MO sequestration.

The parameter to determine favourability of adsorption process $\left(\mathrm{R}_{\mathrm{L}}\right)$ was found to be 0.0153 and 0.0151 for nanocrystals as well as 0.595 and 0.533 for bagasse for experimental and predicted data respectively. This is an indication of favourable adsorption process (Azeez et al. 2018; 2020a,b).

Adsorption intensity $(n)$ from Freundlich isotherm model is a hint to explaining favourable $(n>1)$ or cooperative $(n<1)$ adsorption process. Values of $n$ calculated were 5.92 and 5.68 for nanocrystals and 10.21 and 16.29 for bagasse for experimental and model predicted data respectively. These values validate the favourability of sequestration of MO on both adsorbents (Inyinbor et al. 2017; Adekola et al. 2019).

Adsorption energy that helps determine nature of adsorption process calculated was 14.98 and $15.50 \mathrm{kJmol}^{-1}$ for nanocrystals and 18.59 and $20.26 \mathrm{kJmol}^{-1}$ for bagasse from 
experimental and predicted data respectively. These values suggest chemisorption as the adsorption mode (Azeez et al. 2018; 2020a,b).

\section{Adsorption kinetic study}

Adsorption kinetic data were fitted and explained using pseudo first order, pseudo second order and Elovich kinetics. The predictiveness of each model was adjudged suitable using correlation coefficient $\left(\mathrm{R}^{2}\right)$ and non-linear Chi-square $\left(\chi^{2}\right)$ based on comparatively higher $\mathrm{R}^{2}$ and lower $\chi^{2}$. The order of accuracy for prediction of adsorption kinetics follows pseudo second order $\left(R_{N B G}^{2}-0.999, R_{B G}^{2}-0.999\right)>$ Elovich $\left(R_{N B G}^{2}-0.978, R_{B G}^{2}-0.983\right)>$ pseudo first order $\left(R_{N B G}^{2}-0.969, R_{B G}^{2}-0.941\right)$. Pseudo second order kinetic model was appropriately the best model to predict the kinetics of adsorption of MO on both adsorbents as shown by the correlation coefficient, non-linear Chi-square and close agreement between $\mathrm{q}_{\mathrm{e}}$ experimental and $\mathrm{q}_{\mathrm{e}}$ calculated (Table 3 ). This validates the domination of adsorption process by chemisorption as calculated from the energy of adsorption (Munagapati et al. 2019; Beh et al. 2020; Moawad et al. 2020). Regression model for predicting adsorption kinetics follows a similar trend to experimental data with improved correlation coefficients.

Mechanism of adsorption was performed using Weber and Morris intraparticle diffusion to determine the rate-determining step and the influence of mass transfer resistance on the adsorption of MO (Ojo et al. 2017). Intra-particle diffusion displays a rapid step related to the rate-controlling steps and stable step describing the rate-limiting step (Fig. 8). The rapid step explains the diffusion of MO onto the surfaces of adsorbents while the stable step designates preponderance of intra-particle diffusion in the adsorption process. Two-stage plots with deviations from origin submit that intra-particular diffusion mechanism was involved in the adsorption process but not the sole rate-determining step (Adekola et al. 2019; Azeez et 1., 2020a).

\section{Adsorption thermodynamic study}

The values of $\Delta \mathrm{H}^{\mathrm{o}}, \Delta \mathrm{S}^{\mathrm{o}}$ and $\Delta \mathrm{G}^{\mathrm{o}}$ indicating energetics and spontaneity of the adsorption process of $\mathrm{MO}$ on bagasse and nanocrystals were evaluated from thermodynamic parameters (Table 4).

Negative values of $\Delta \mathrm{H}^{\mathrm{o}}$ imply exothermic nature of adsorption process of $\mathrm{MO}$ on both adsorbents with reduced randomness as shown by positive $\Delta S^{0}$ values signifying direct interaction between adsorbate and adsorbents (Suganya et al. 2017; Adejumo et al. 2020). 
The values of $\Delta \mathrm{G}^{\mathrm{o}}$ range from -12.57 to $-13.39 \mathrm{kJmol}^{-1}$ reducing with increasing temperature. These indicate spontaneous adsorption process at all temperatures but more favourably feasible at a higher temperature (Munagapati et al. 2019. Regression model predicted approximately the same magnitude of energetics and spontaneity of the adsorption process

\section{Conclusions}

Cellulose nanocrystals using acid hydrolysis method were successfully extracted from sugarcane bagasse, characterized and investigated for their adsorptive capacity for anionic dye removal. The disappearance of uronic ester peak of hemicellulose/lignin indicated cellulose extraction while higher carbon content, greater crystallinity index, nano range of particles and larger porosity are parameters that better defined cellulose nanocrystals. A 2fold improvement in monolayer adsorption capacity was obtained for cellulose nanocrystals over bagasse. Adsorption processes were best described by Langmuir isotherm on nanocrystals whereas Freundlich isotherm was best suited for bagasse. Adsorption processes on both adsorbents were spontaneous, exothermic and best fitted to pseudo second order kinetics ensuing chemisorption. Polynomial regression model appropriately predicted equations that best describe the effects of different batch adsorption parameters on MO removal with better fittingness than experimentally generated data

\section{Declarations}

\section{Ethics approval and consent to participate}

Not applicable

\section{Consent for publication}

Not applicable

\section{Availability of data and materials}

All data generated during this study are included in this manuscript

\section{Competing interest}

Authors declare no conflicts of interest in this study

\section{Funding}

Not applicable

\section{Authors' contribution}

LA synthesized, characterized cellulose nanocrystals, did the manuscript write-up and regression modelling. AL coordinated the collection of bagasse and preparation of solutions in the laboratory. AOO and HK assisted in calculation and manuscript write-up. 


\section{Acknowledgement}

Not applicable

\section{References}

Abitbol T, Rivkin A, Cao Y, Nevo Y, Abraham E, Ben-Shalom T, Lapidot S, Shoseyov O (2016) Nanocellulose, a tiny fiber with huge applications, Curr Opin Biotechnol 39: 76-88.

Abraham E, Deepa B, Pothan LA, Jacob, M, Thomas, S, Cvelbar, U, Anandjiwala R (2011) Extraction of nanocellulose fibrils from lignocellulosic fibres: A novel approach. Carbohydr Polym 86:1468- 1475

Adejumo AL, Azeez L, Oyedeji AO, Adetoro RO, Aderigbigbe FA (2020). Nanostructured and surface functionalized corncob as unique adsorbents for anionic dye remediation. SN Appl Sci 2: 301. https://doi.org/10.1007/s42452-020-2109-5

Adekola FA, Ayodele SB, Inyinbor AA (2019) Efficient Rhodamine B Removal Using Acidand Alkaline-Activated Musa paradisiaca Biochar. Pol J Environ Stud 28(5): 3063 3070

Alves MJ, Cavalcanti IV, de Resende MM, Cardoso VL, Reis MH (2016) Biodiesel dry purification with sugarcane bagasse. Ind Crops Prod 89: 119-127

Anitha T, Kumar PS, Kumar KS (2016) Synthesis of nano-sized chitosan blended polyvinyl alcohol for theremoval of Eosin Yellow dye from aqueous solution. J Water Proc Eng 13: $127-136$

Assouline S, Russo D, Silber A, Or D (2015) Balancing water scarcity and quality for sustainable irrigated agriculture, Water Resour. Res 51: 3419-3436

Azeez L, Salau AK, Adewuyi SO, Osineye SO, Tijani KO, Balogun RO (2015) Safety evaluation of Osun river water containing heavy metals and volatile organic compounds (VOCs) in rats. Niger J Physiol Sci 30:103-109

Azeez L, Lateef A, Adebisi SA, Oyedeji AO (2018) Novel biosynthesized silver nanoparticles from cobweb as adsorbent for Rhodamine B: Equilibrium isotherm, Kinetic and Thermodynamic studies. Appl Water Sci 8: 32.

Azeez L, Lateef A, Adejumo AL, Adeleke TA, Adetoro RO, Mustapha Z (2020a) Adsorption Behaviour of Rhodamine B on hen feather and corn starch functionalized with green synthesized silver nanoparticles (AgNPs) mediated with cocoa pod extracts. Chem Afr $\quad 3: 237-250$ 
Azeez L, Adejumo AL, Asaolu SS, Adeoye MD, Adetoro RO (2020b) Functionalization of rice husk with Ortho-phosphoric acid enhanced adsorptive capacity for anionic dye removal. Chem Afr 3: 457-467.

Bano S, Negi YS (2017) Studies on cellulose nanocrystals isolated from groundnut shells. Carbohydr Polym 157: 1041-1049

Beh JH, Lim TH, Lew JH, Lai JC (2020) Cellulose nanofibril-based aerogel derived from sago pith waste and its application on methylene blue removal. Int J Biol Macromol 160: $836-845$

Brandão PC, Souza TC, Ferreira CA, Hori CE, Romanielo LL (2010) Removal of petroleum hydrocarbons from aqueous solution using sugarcane bagasse as adsorbent. J Hazard Mat 175: 1106-1112

Buthiyappan A, Gopalan J, AbdulRaman A (2019) Synthesis of iron oxides impregnated

green adsorbent from sugarcane bagasse: Characterization and evaluation of adsorption efficiency. J Environ Manag 249: 109323

Chan CH, Chia CH, Zakaria S, Sajab MS, Chin SX (2015) Cellulose nanofibrils: a rapid adsorbent for the removal of methylene blue. RSC Adv 5: 18204-18212.

Chen W, Yu H, Liu Y, Hai Y, Zhang M, Chen P (2011) Isolation and characterization of cellulose nanofibers from four plant cellulose fibers using a chemical-ultrasonic process. Cellulose 18:433-442

Chen W, Li Q, Cao J, Liu Y, Li J, Zhang J, Luo, S, Yu H (2015) Revealing the structures of cellulose nanofiber bundles obtained by mechanical nanofibrillation via TEM observation. Carbohydr Polym 117: 950 - 956

Dubinin MM, Radushkevich LV (1947) The equation of the characteristic curve of the activated charcoal. Proc Acad Sci USSR Phys Chem Sect 55: 331-337.

Dufresne A (2013) Nanocellulose: a new ageless bionanomaterial. Mater Today 16: 220-227.

El Achaby M, Fayoud N, Figueroa-Espinoza MC, Ben youcef H, Aboulkas A (2018) New highly hydrated cellulose microfibrils with a tendril helical morphology extracted from agro waste material: application to removal of dyes from waste water. RSC Adv 8: $5212 \quad-5224$

Ferreira FV, Mariano M, Rabelo SC, Gouveia RF, Lona LMF (2018) Isolation and surface modification of cellulose nanocrystals from sugarcane bagasse waste: From a microto a nano-scale view. Appl Surf Sci 436: 1113-1122

Freundlich HMF (1906) Over the adsorption in solution. J Phys Chem 57: 385-470. 
Gautam PK, Singh A, Misra K, Sahoo AK, Samanta SK (2019) Synthesis and applications of biogenic nanomaterials in drinking and wastewater treatment J Env Manag 231: 734748

Hakkarainen T, Koivuniemi R, Kosonen M, Escobedo-Lucea C, Sanz-Garcia C, Vuola J, Valtonen J, Tammela P, Mäkitie A, Luukko K, Yliperttula M, Kavola H (2016) Nanofibrillar cellulose wound dressing in skin graft donor site treatment, J Control Release 244: 292-301.

Hosseinidoust Z, Alam M, Sim G, Tufenkji N, van de Ven T (2015) Cellulose nanocrystals with tunable surface charge for nanomedicine, Nanoscale 7: 16647-16657.

Huang R, Liu Q, Huo J, Yang B (2017) Adsorption of methyl orange onto protonated crosslinked chitosan. Arabian J Chem 10: 24-32.

Hurtubise F, Krassig H (1960) Classification of fine structural characteristics in cellulose by infrared spectroscopy. Anal Chem 32(2):177-181

Inyinbor AA, Adekola FA, Olatunji GA (2017) Kinetics and isothermal modelling of liquid phase adsorption of Rhodamine B onto urea modified Raphia hookerie epicarp. Appl Water Sci 7(6): 3257 - 3266.

Jiang F, Dinh DM, Hsieh YL (2017). Adsorption and desorption of cationic malachite green dye on cellulose nanofibril aerogels. Carbohydr Polym 173: 286-294.

Jonoobi M, Oladi R, Davoudpour Y, Oksman K, Dufresne A, Hamzeh Y, Davoodi R (2015) Different preparation methods and properties of nanostructured cellulose from various natural resources and residues: a review. Cellulose 22:935-969

Jorfi M, Johan FE (2015) Recent advances in nanocellulose for biomedical applications, J

Appl Polym Sci 132: 1-19.

Keyhanian F, Shariati S, Faraji M, Hesabi M (2016) Magnetite nanoparticles with surface modification for removal of methyl violet from aqueous solutions. Arab J Chem 9: S348-S354

Kruer-Zerhusen N, Cantero-Tubilla B, Wilson DB (2018) Characterization of cellulose crystallinity after enzymatic treatment using Fourier transform infrared spectroscopy (FTIR). Cellulose 25: 37 - 48

Kumar A, Negi YS, Choudhary V, Bhardwaj NK (2014) Characterization of cellulose nanocrystals produced by acid-hydrolysis from sugarcane bagasse as agro-waste. $\mathbf{J}$

Mat Phys Chem 2(1): 1-8.

Langmuir I (1918) The adsorption of gases on plane surfaces of glass, mica and platinum. ACS 40: 1361-1403. 
Liu C, Li B, Du H, Lv D, Zhang Y, Yu G, Mu X, Peng H (2016) Properties of nanocellulose isolated from corncob residue using sulfuric acid, formic acid, oxidative and mechanical methods. Carbohyd Polym 151: 716-724

Mahfoudhi N, Boufi S (2017) Nanocellulose as a novel nanostructured adsorbent for environmental remediation: a review. Cellulose 24: 1171 - 1197

Maya S, Anjali B (2018) Superabsorbent nanocomposite from sugarcane bagasse, chitin and clay: Synthesis, characterization and swelling behaviour. Carbohydr Polym 193: 281288

Moawad MN, El-Sayed AAM, El-Naggar NA (2020) Biosorption of cadmium and nickel ions using marine macrophyte, Cymodoceanodosa. Chem Ecol 36(5): 458 - 474

Munagapati VS, Wen J-C, Pan C-L, Gutha Y, Wen J-H (2019) Enhanced adsorption performance of Reactive Red 120 azo dye from aqueous solution using quaternary amine modified orange peel powder. J Mol Liq 285: 375-385

Nechyporchuk O, Belgacem MN, Bras J (2016) Production of cellulose nanofibrils: A review of recent advances. Ind Crops Prod 93: 2-25

Nelson ML, O’Connor RT (1964) Relation of certain infrared bands to cellulose crystallinity and crystal lattice type. Part 11. A new infrared ratio for estimation of crystallinity in celluloses I and II. J Appl Polym Sci 8: 1325-1341.

Neto, WPF, Silverio HA, Dantas, NO, Pasquinia D (2013) Extraction and characterization of cellulose nanocrystals from agro-industrial residue - Soy hulls. Ind. Crops Prod 42: $480-488$

Ojedokun AT, Bello OS (2017) Liquid phase adsorption of Congo red dye on functionalized corncobs. J Dispersion Sci Technol 38(9): 1285-1294.

Ojo TA, Ojedokun AT, Bello OS (2017) Functionalization of powdered walnut shell with orthophosphoric acid for Congo red dye removal. Particlate Sci Technol 37(1): 74 85.

Oliveira FB, Bras J, Pimenta MTB, Curvelo AAS, Belgacem MN (2016) Production of cellulose nanocrystals from sugarcane bagasse fibers and pith. Ind Crops Prod 93: 4857

Pavithra KG, Kumar PS, Jaikumar V, Rajan PS (2019) Removal of colorants from wastewater: A review on sources and treatment strategies. J Ind Eng Chem 75: 1-19

Pehlivan E, Tran HT, Ouédraogo WKI, Schmidt C, Zachmann D, Bahadir M (2013) Sugarcane bagasse treated with hydrous ferric oxide as a potential adsorbent for the removal of $\quad \operatorname{As}(V)$ from aqueous solutions. Food Chem 138: 133-138 
Phanthong P, Reubroycharoen P, Hao X, Xu G, Abudula A, Guan G (2018) Nanocellulose: Extraction and application. Carbon Resour. Convers 1(1): 32 - 43

Saravanan A, Kumar PS, Yaashikaa PR, Kanmani S, Varthine RH, Muthu CMM, Yuvaraj D (2019) Modelling on the Removal of Dye from Industrial Wastewater Using Surface Improved Enteromorpha intestinalis. Int J Environ Res 13(2): 1-18.

Suganya S, Kumar PS, Saravanan A, Rajan PS, Ravikumar C (2017) Computation of adsorption parameters for the removal of dye from wastewater by microwave assisted sawdust: theoretical and experimental analysis. Environ Toxicol Pharmacol 50: 45-57

Suman S, Kardam A, Gera M, Jain VK (2015) A novel reusable nanocomposite for complete removal of dyes, heavy metals and microbial load from water based on nanocellulose and silver nano-embedded pebbles. Environ Technol 36(5-6): 707-714

Tempkin MI, Pyzhev V (1940) Kinetics of ammonia synthesis on promoted iron catalyst.

Acta Phys Chim USSR. 12: 327-356.

Theivasanthi T, Christma FLA, Adeleke JT, Subash CBG, Ravichandran R (2018) Synthesis and characterization of cotton fiber-based nanocellulose. Int $\mathrm{J}$ Biol Macromol 109:832- $\quad 836$

Wang J, Liu X, Jin T, He H, Liu L (2019) Preparation of nanocellulose and its potential in reinforced composites: A review. J Biomat Sci Polym 30(11): 919 - 946.

Yang X, Liu H, Han F, Jiang S, Liu L, Xia Z (2017a) Fabrication of cellulose nanocrystal

from Carex meyeriana Kunth and its application in the adsorption of methylene blue. Carbohydr. Polym175: 464-472

Yang X, Han F, Xu C, Jiang S, Huang L, Liu L, Xi Z (2017b) Effects of preparation methods on the morphology and properties of nanocellulose (NC) extracted from corn husk. Ind Crops Prod 109: 241-247.

Zhang Y, Tong D, Song K (2013) A comparative analysis on the longitudinal compression characteristics of juvenile and mature northeast Chinese ash (Fraxinus mandshurica Rupr.) subjected to alkaline treatment. BioResour 8(2): 1963-1975.

Zhang H, Luan Q, Tang H, Huang F, Zheng M, Deng Q, Xiang X, Yang C, Shi J, Zheng C, Zhou Q (2017) Removal of methyl orange from aqueous solutions by adsorption on cellulose hydrogel assisted with $\mathrm{Fe}_{2} \mathrm{O}_{3}$ nanoparticles. Cellulose 24: 903-914 


\section{Figures}
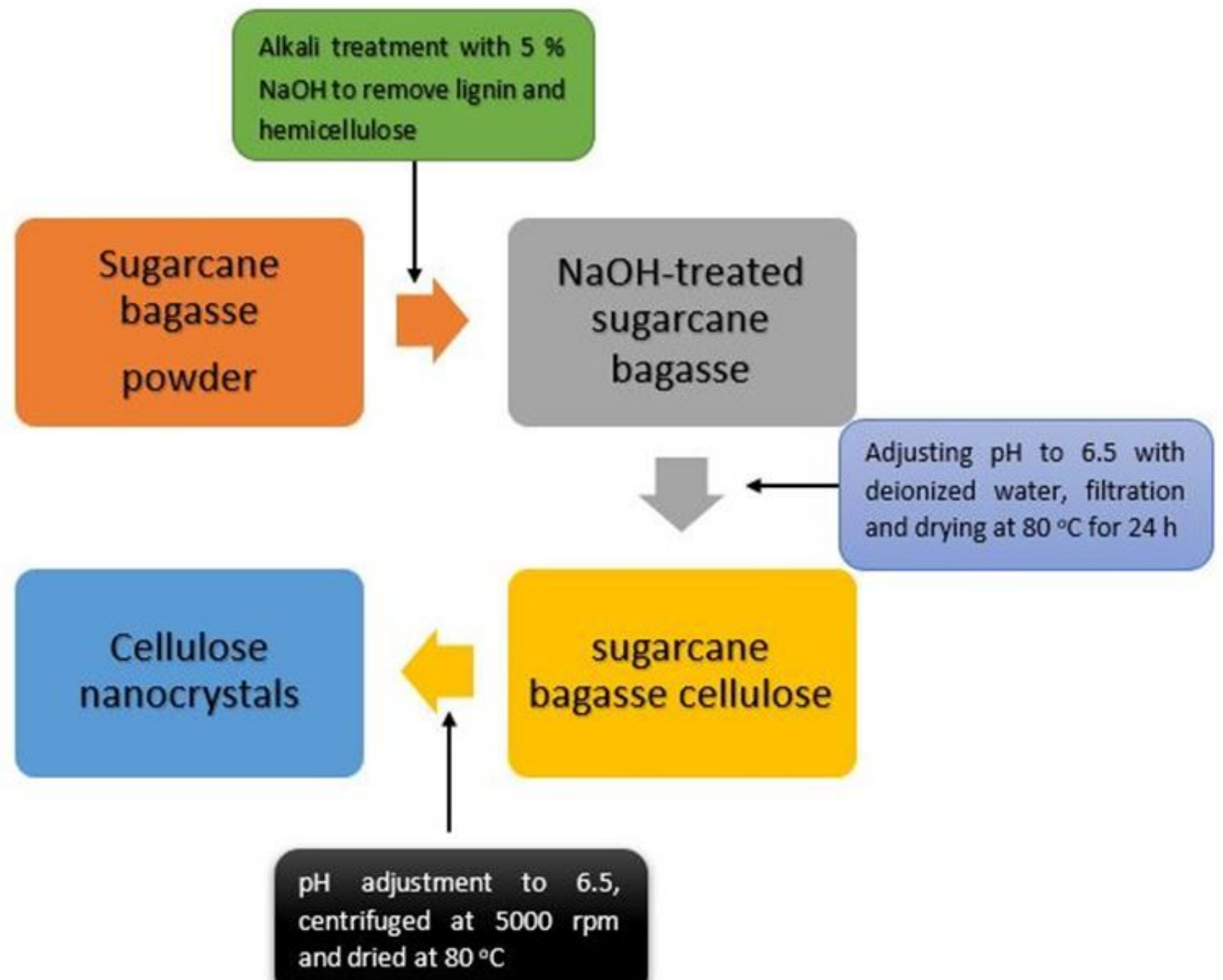

Figure 1

Scheme for the synthesis of cellulose nanocrystals from sugarcane bagasse. 

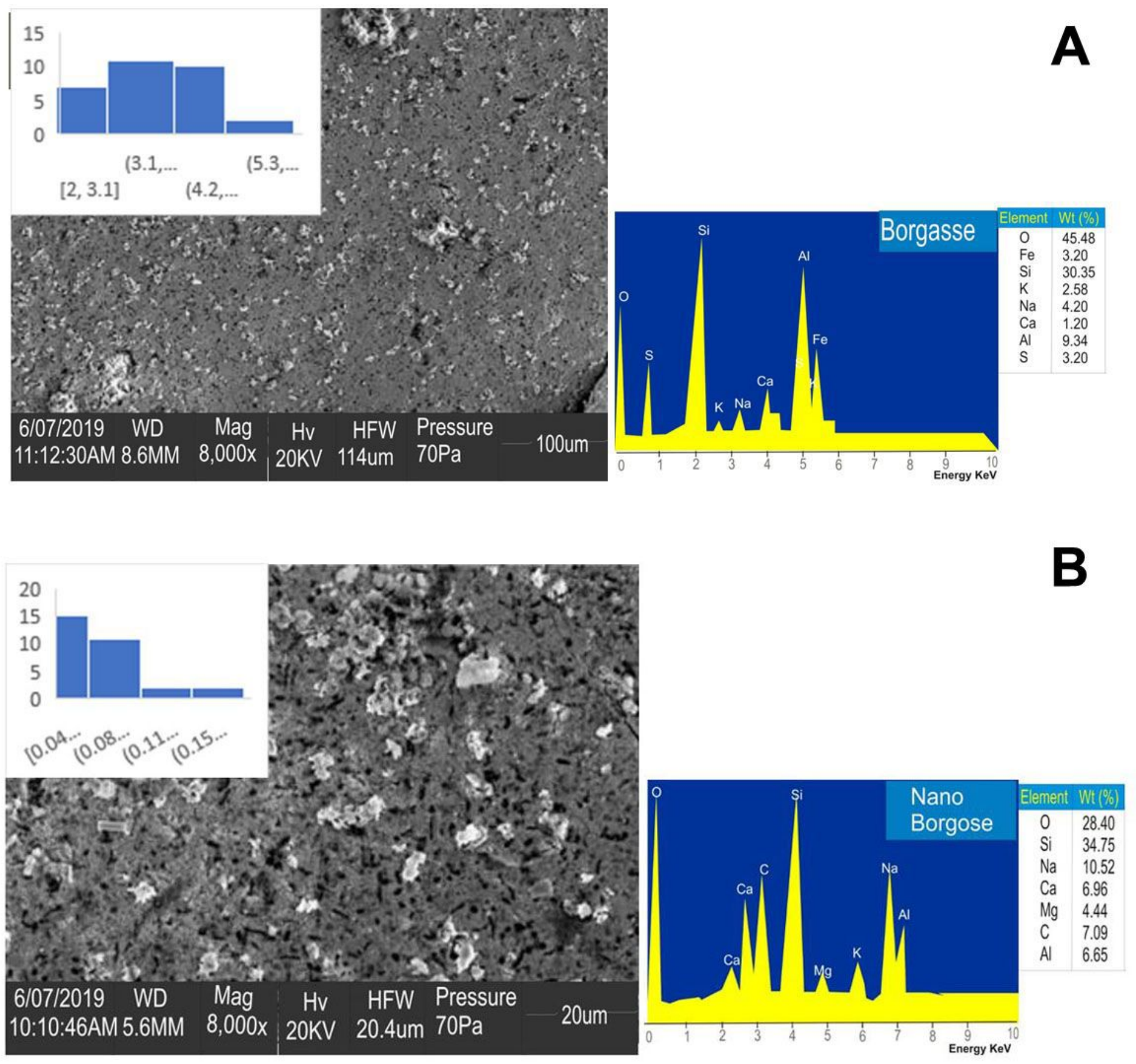

\section{Figure 2}

A: SEM image and elemental composition of sugarcane bagasse. B: SEM image and elemental composition of cellulose nanocrystals. 

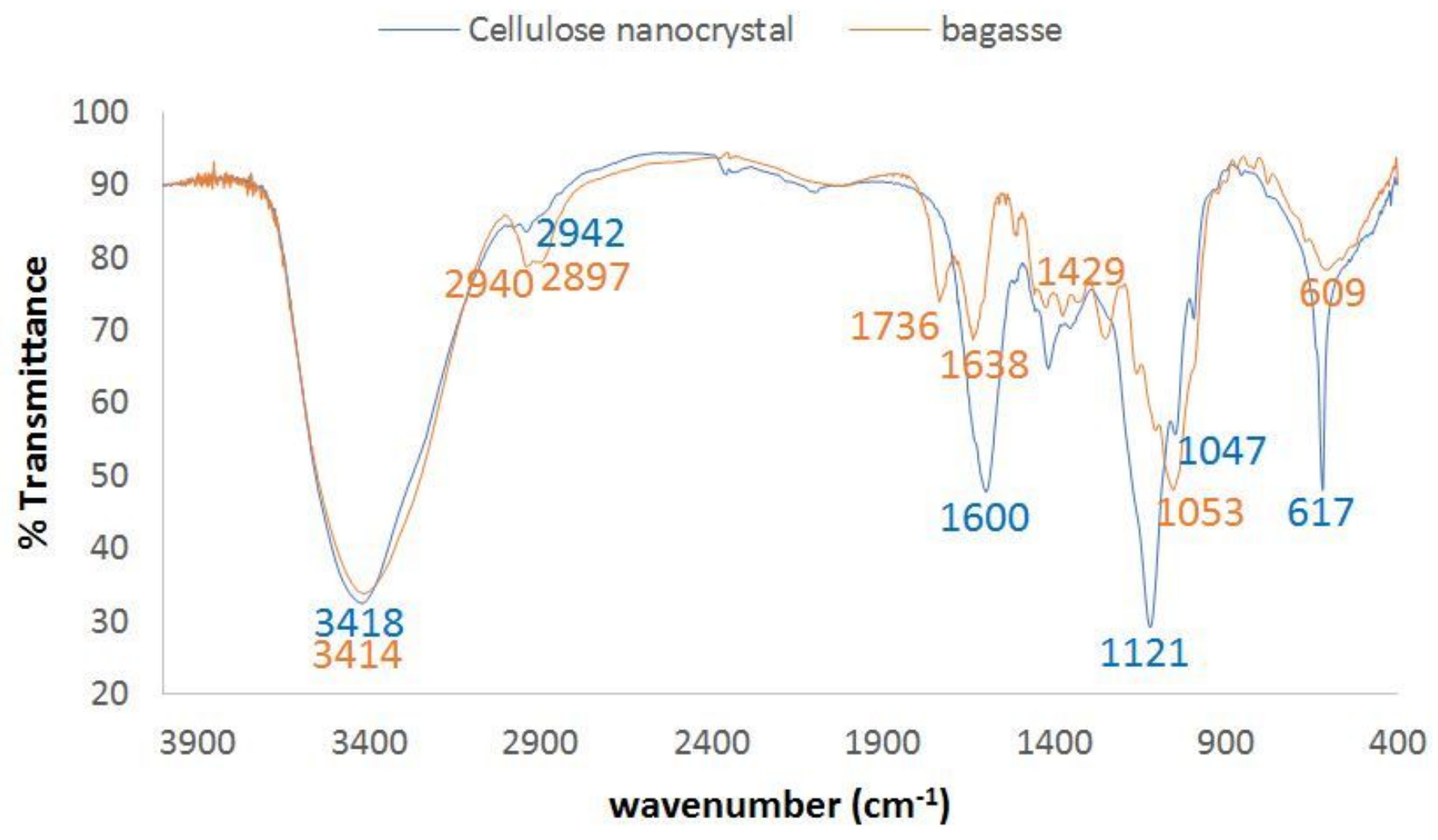

Figure 3

FTIR spectra of cellulose nanocrystals and sugarcane bagasse. 


$$
\longrightarrow B G(\operatorname{Exp}) \longrightarrow B G(\text { Pred })-N B G(\operatorname{Exp}) \longrightarrow \text { NBG (Pred) }
$$

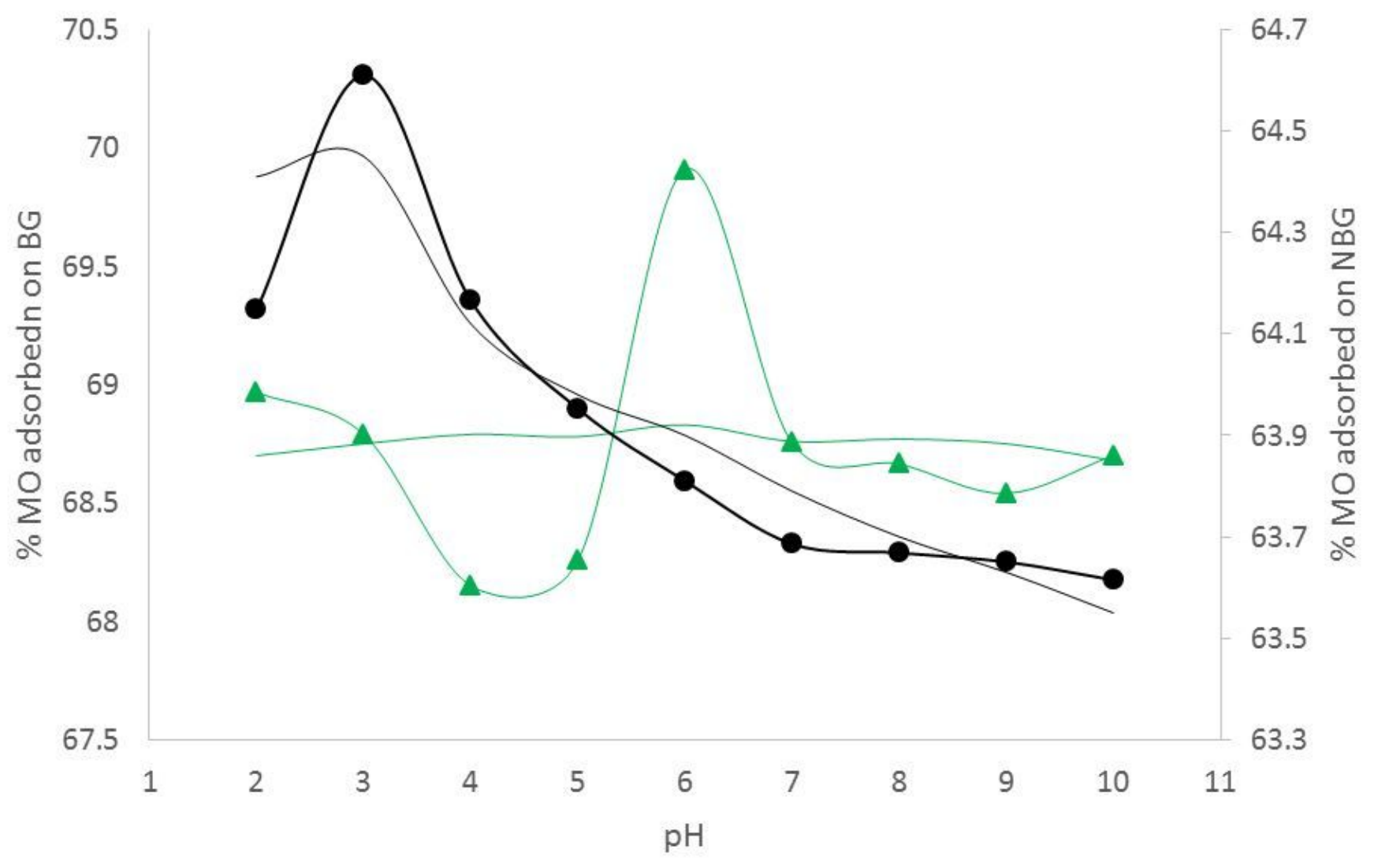

Figure 4

Effects of $\mathrm{pH}$ on percentage adsorption of $\mathrm{MO}$ and model prediction. 
$\longrightarrow$ NBG (Exp) $\longrightarrow$ NBG (Pred) $\longrightarrow$ BG (Exp) $\longrightarrow$ BG (Pred)

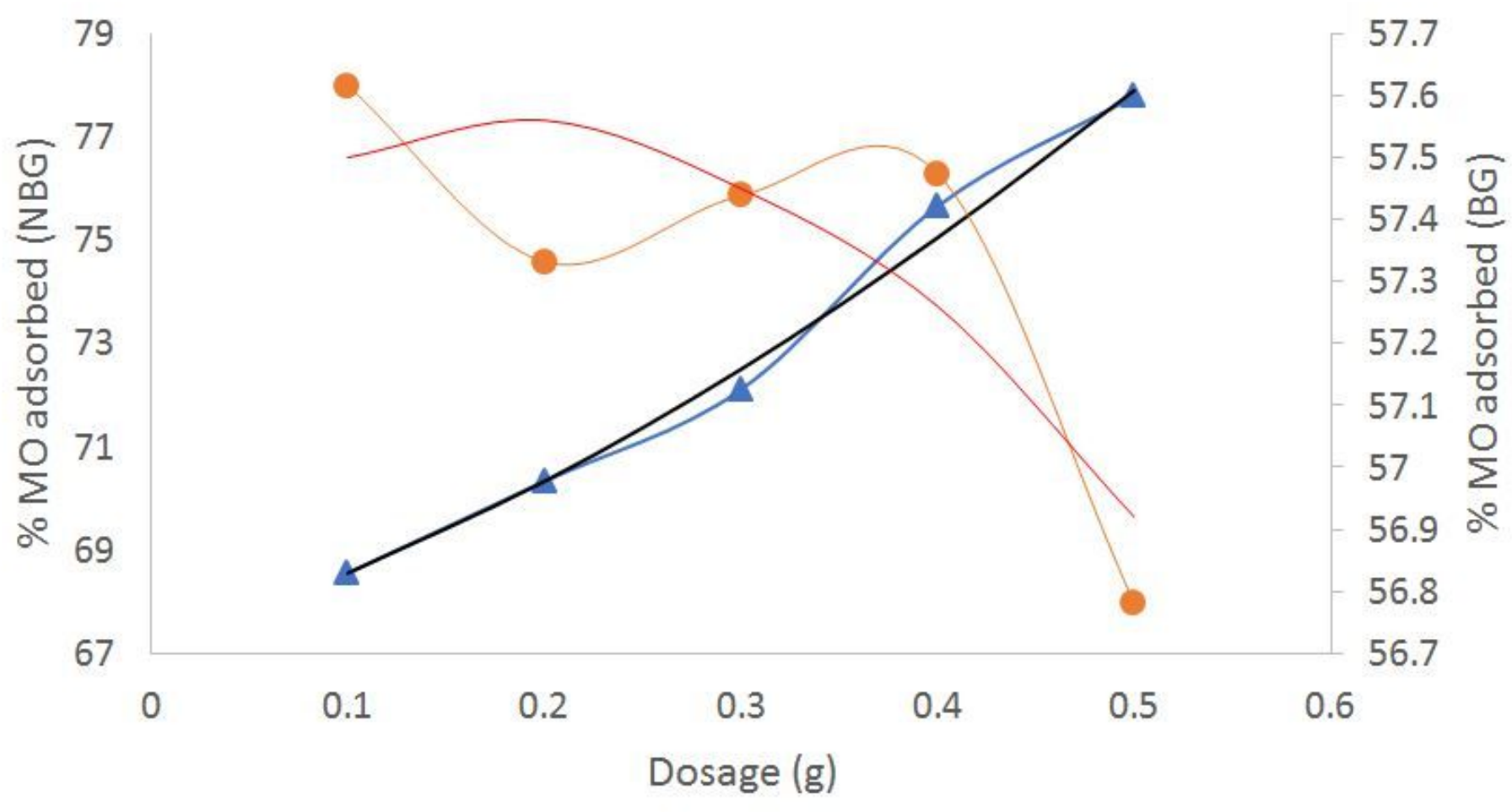

Figure 5

Effects of dosage on percentage adsorption of $\mathrm{MO}$ and model prediction. 

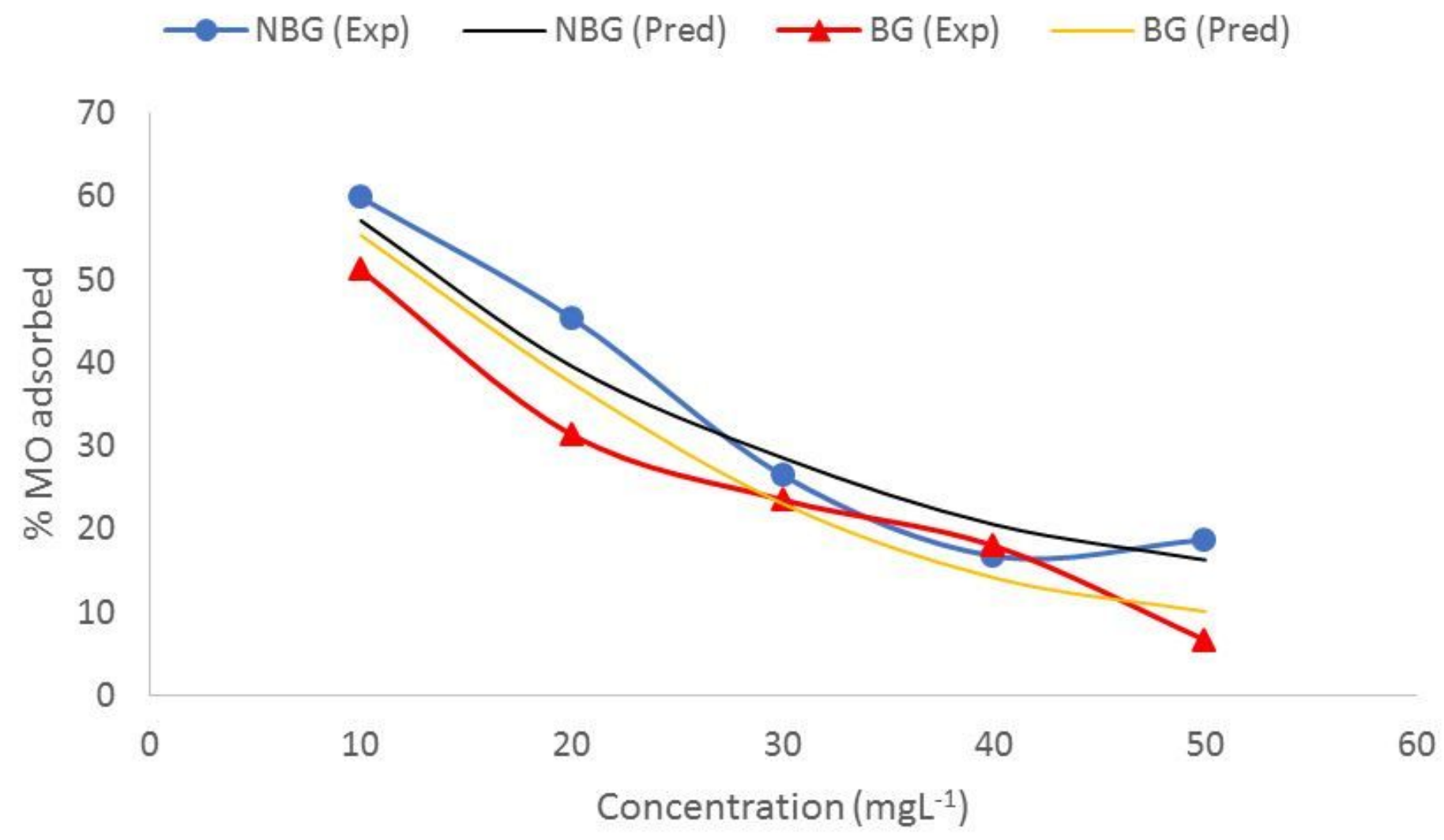

Figure 6

Effects of initial concentration of $\mathrm{MO}$ on percentage adsorption and model prediction. 


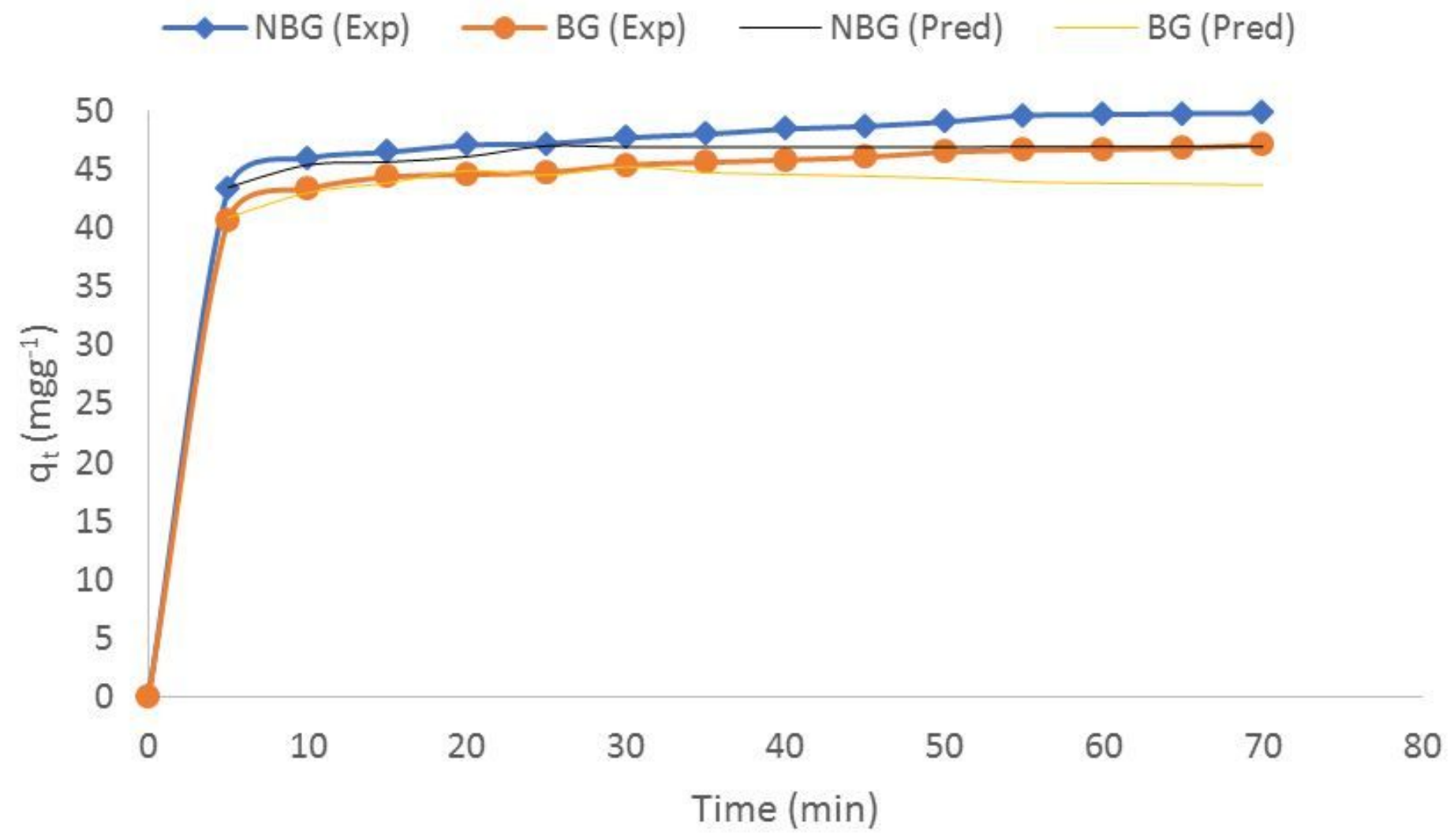

Figure 7

Quantity of MO adsorbed with respect to time and model prediction. 


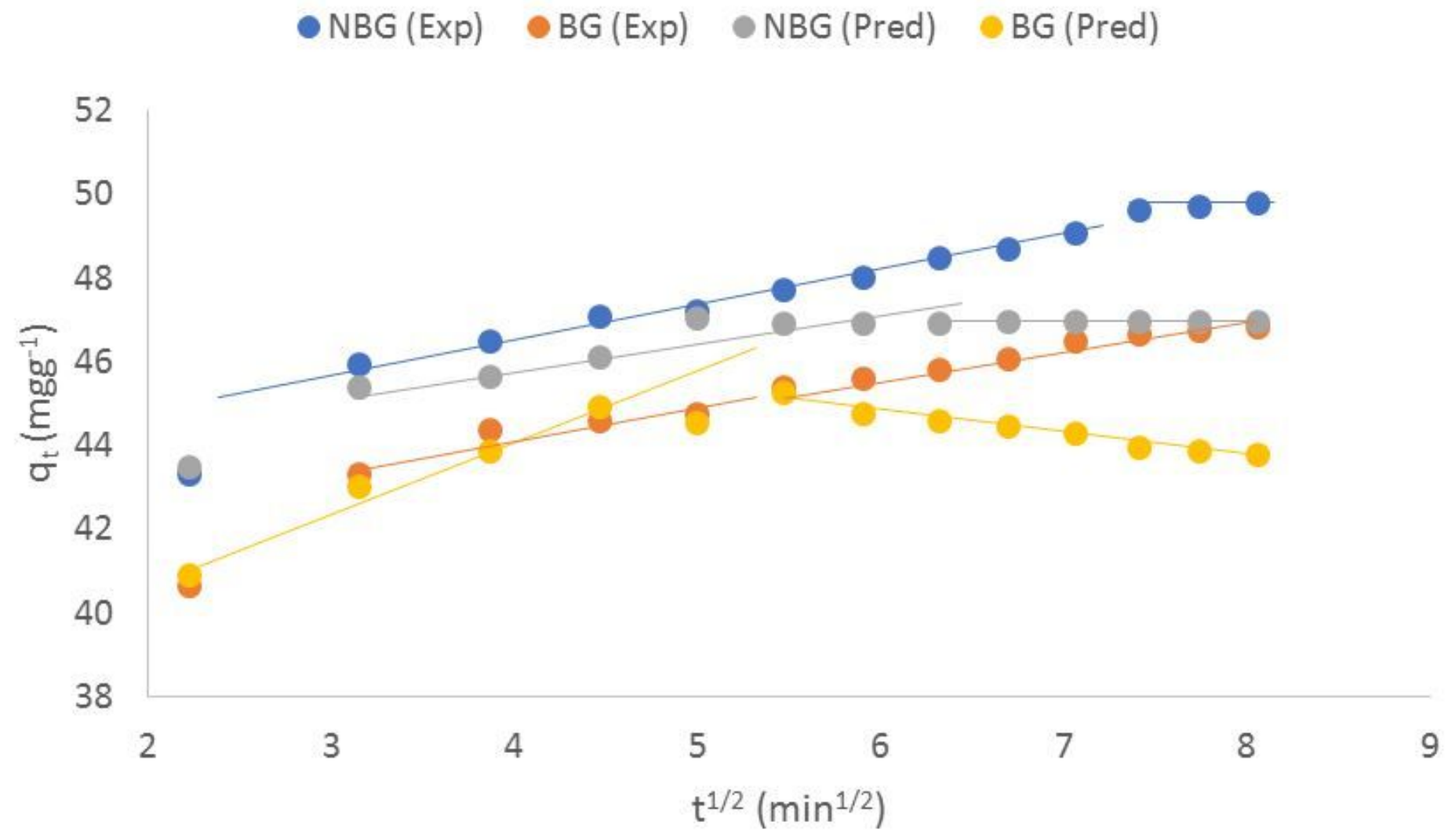

Figure 8

Plot of intraparticle diffusion for adsorption of $\mathrm{MO}$ and model prediction.

$\longrightarrow B G($ Exp) $\longrightarrow$ BG (Pred) $\longrightarrow$ NBG $($ Exp) $\longrightarrow$ NBG (Pred)

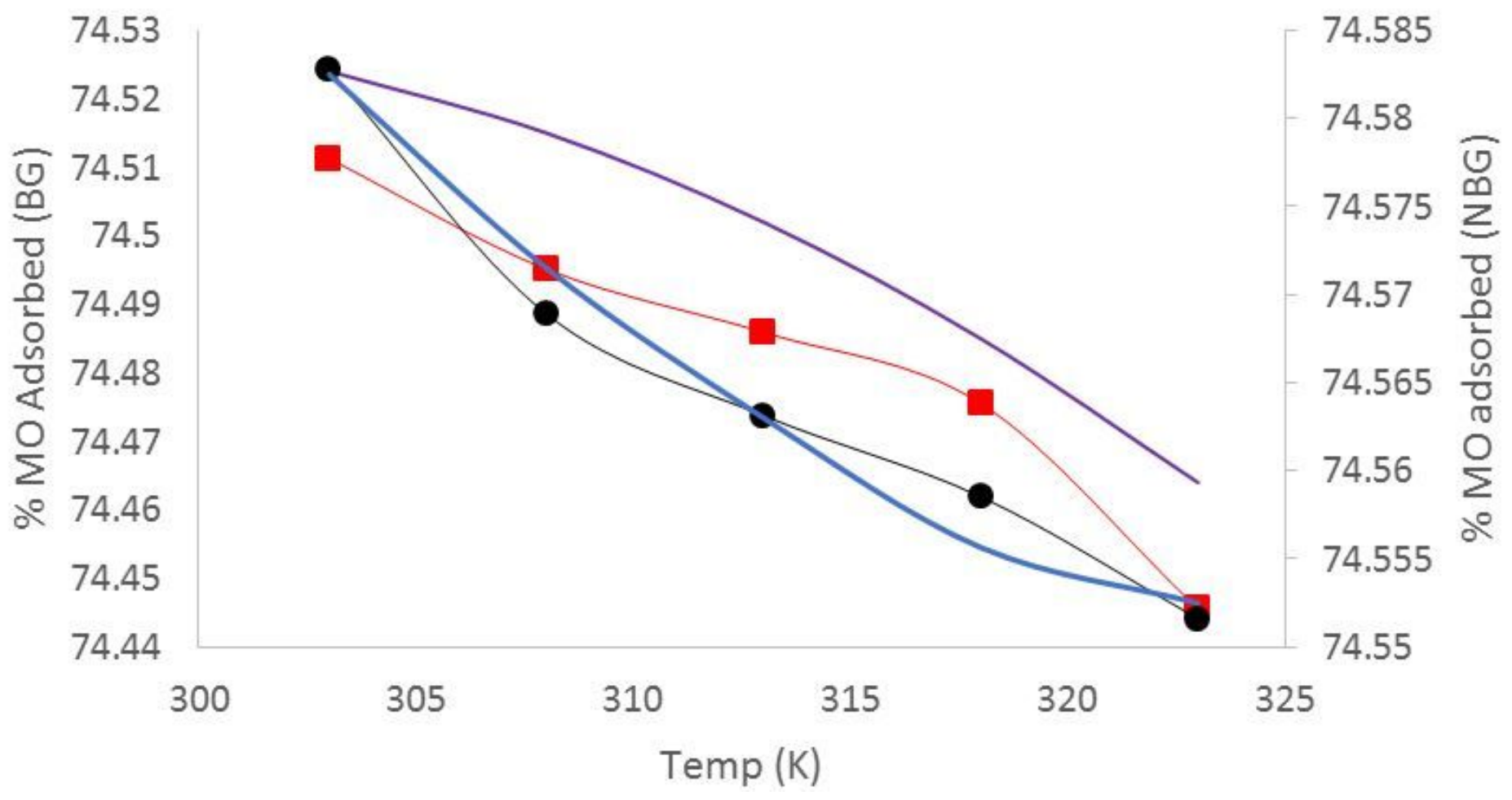


Figure 9

Effects of temperatures on percentage adsorption of $\mathrm{MO}$ and model prediction.

\section{Supplementary Files}

This is a list of supplementary files associated with this preprint. Click to download.

- graphicabstract.JPG 